\title{
Rotator cuff muscle stem cells: the double-edged sword in the skeletal muscle
}

\author{
Yong-Soo Lee ${ }^{1,2}$, Ja-Yeon Kim ${ }^{1}$, Seok Won Chung ${ }^{1}$ \\ ${ }^{1}$ Department of Orthopedic Surgery, Konkuk University School of Medicine, Seoul, Republic of Korea; ${ }^{2}$ Joint Center, Barunsesang Hospital, \\ Seongnam-si, Gyeonggi-do, Republic of Korea \\ Correspondence to: Seok Won Chung, MD, PhD. Department of Orthopedic Surgery, Konkuk University School of Medicine, 120-1 Neungdong-ro \\ (Hwayang-dong), Gwangjin-gu, Seoul 143-729, Republic of Korea. Email: smilecsw@gmail.com. \\ Provenance and Peer Review: This article was commissioned and reviewed by the Section Editor Dr. Qian Liu (Department of Orthopaedics, The \\ Second Xiangya Hospital, Central South University, Changsha, China). \\ Comment on: Schubert MF, Noah AC, Bedi A, et al. Reduced Myogenic and Increased Adipogenic Differentiation Capacity of Rotator Cuff Muscle \\ Stem Cells. J Bone Joint Surg Am 2019;101:228-38.
}

Submitted Jan 14, 2020. Accepted for publication Jan 29, 2020.

doi: $10.21037 / \mathrm{atm} .2020 .02 .32$

View this article at: http://dx.doi.org/10.21037/atm.2020.02.32

Rotator cuff tear (RCT) is a representative muscletendinous disease-causing shoulder pain (1), and recently, its prevalence rate is remarkably increasing by an aging population and various sports activities $(2,3)$. For RCTs, surgical repair is prevalent and has been a commonly accepted treatment, especially when the conservative management was failed (4). Nevertheless, failure of rotator cuff healing after repair is common and is one of major post-surgical complications (5), though the arthroscopic repair techniques have been advancing steadily. Most of all, fatty degeneration in muscle is a critical detrimental cause of poor functional outcome due to its irreversible property $(6,7)$. Although the precise mechanisms of muscle fatty infiltration are not fully determined yet, numbers of studies have assumed that muscle fat accumulation is caused by adipogenic differentiation of the stem cells in muscle (8-10).

Stem cells have the potential to differentiate into multilineage of tissues and can theoretically be stimulated to undergo transition to a preferred lineage such as bone, cartilage, tendon, and muscle, thus recreating a specific tissue (11). Therefore, recently, various stem cell-based therapeutic approaches have been attempted to repair the injured tissue (12). But, as above mentioned, satellite cells can also differentiate into adipocyte by various degenerative factors including aging, muscle injury, mechanical unloading, and hormonal imbalance (13-16). Thus, understanding of the fine-tuned balance of stem cell differentiation has considerable interest in biological augmentation of rotator cuff healing.

In "The Fournal of Bone and Foint Surgery (American volume)", Schubert et al. reported that rotator cuff satellite cells are more disinclined to myogenic differentiation, rather prone to adipogenic differentiation compared with that from gastrocnemius muscles (17). By isolation of the specifically labeled satellite cells from rotator cuff muscle and gastrocnemius muscles in tamoxifen-stimulated $\operatorname{Pax} 7^{\text {CreERT2 }}: R 26 R^{\text {tdTomato }}$ mice, they evaluated the potential of satellite cells to differentiating into myogenic or adipogenic lineage. The rotator cuff satellite cells revealed a $23 \%$ reduced myogenic capacity and a 4.3 -fold increased adipogenic differentiation compared with gastrocnemius satellite cells. Although there was no significant difference in gene expression of desmin and myomaker, the expression of myogenic regulatory factor 4 (MRF4), the late-muscle differentiation marker was remarkably decreased (an $87 \%$ reduction) in rotator cuff satellite cells. With respect to adipogenic differentiation, the representative adipogenic transcription factor peroxisome proliferator-activated receptor gamma $(\operatorname{PPAR} \gamma)$ and a carrier protein for fatty acids fatty acid binding protein 4 (FABP4) were significantly increased in rotator cuff satellite cells (a 12-fold and a 65 -fold increase, respectively). However, there was no significant differences in the expression of adiponectin and CCAAT-enhancer-binding protein-alpha $(\mathrm{C} / \mathrm{EBPa})$ between the groups. They also identified rotator cuff muscle-specific 180 hypomethylated regions and 175 hypermethylated 
regions compared with gastrocnemius by evaluation of any epigenetic difference between both groups of satellite cells. Gene ontology analysis of relevant biological processes and molecular function predictions of the differentially methylated regions revealed that the top 15 genes revealing higher methylation differences are associated with embryonic development and limb morphogenesis. They also suggested that the molecular functions of high-ranked genes are closely related to transcription-factor activity and lipid metabolism regarding adipogenesis.

Although this study presents very interesting and meaningful findings that satellite cells in rotator cuff muscle have distinct differentiation potential compared with that from other type of muscles such as the gastrocnemius muscles, there are several concerns to be considered. Because they cultured the isolated satellite cells in adipogenic media only and analyzed the capacity of both myogenic and adipogenic differentiation, this examination seems asymmetric assessment showing only the susceptibility of both satellite cells against adipogenic condition. In addition, the proportion of satellite cells between rotator cuff and gastrocnemius muscles should be considered due to the fact that the satellite cells are a functionally heterogeneous population showing many differences in their gene expression profile, myogenic differentiation tendency, and pluripotency to assume nonmyogenic fates (18).

In general, for an efficient repair of tissue damage, muscle stem cells are activated by muscle injury and undergo self-renewal process (19) However, in certain cases, they can enter the adipogenic process by activation of the crucial transcription factors $\mathrm{C} / \mathrm{EBP} \alpha$ or PPAR $\gamma$. The fate decision of stem cells is ultimately derived from an imbalance between myogenic and adipogenic environment. In view of this context, the important thing is what kind of factors decide the fate of stem cell to select which edge of the sword. To identify the potent molecule(s) associated with a myogenic or adipogenic capacity of the satellite cells, they examined a limited number of molecules with regard to each differentiation. Various transcription factors or molecular mediators are known to be involved in decision of stem cell fate. It has been known that myogenic differentiation 1 (MyoD) and myogenic factor 5 (Myf5) are master regulators of skeletal muscle formation during embryogenesis and postnatal myogenesis (20). However, such myogenic regulatory factors also known to be involved in muscle regeneration. MyoD expression is nearly absent in quiescent satellite cells, while its expression is augmented in activated muscle stem cells by muscle injury or exercise (21). Up to date, a variety of myogenic regulatory factors and their upstream regulators in the field of skeletal muscle formation and regeneration are elucidated (22). Muscle fatty infiltration is induced by the ectopic fat accumulation in damaged muscle and thought to be caused by a defect of proper muscle regeneration process after injury $(10,23)$. Therefore, identification of the molecular mediators involved in muscle regeneration or intramuscular fat accumulation seems to be a promising direction.

Recently, biologic augmentation for rotator cuff repair has been attracting the attention due to its promising potential to regenerate damaged tissues effectively, and various approaches have been tried to improve the outcome of rotator cuff surgeries. Among them, stem cell-based therapies have shown encouraging results to replenish damaged tissue for better healing. However, paradoxically, they are plagued by the limitation, their pluripotency. Stem cells can differentiate into various cell types and they can also spread to other areas of the body causing undesired mutations or alteration of their genetic profile. Therefore, comprehensive understanding of the properties of muscle stem cells and various biologic approaches need to be preceded first before consideration for human clinical trials.

On the other hand, a recent study reported that RCTinduced muscle fatty infiltration is intermediated by FABP4, unlike adipogenesis of muscle stem cells (24). In that study, authors suggested that FABP4 gene expression is induced by RCT through direct binding of hypoxia inducible factor 1 (HIF1) to the FABP4 promoter, which leads to ectopic fat accumulation in injured muscle. As an extended study, they also evaluated that the muscle injury-induced ectopic fat accumulation is repressed noticeably by FABP4 inhibitor, and that FABP4 inhibitor further improves muscle tensile strength (25). Thus, the application of other approaches besides stem cell-based therapy would be a considerable way to improve muscle degeneration with respect to RCT.

\section{Acknowledgments}

Funding: This study was supported by the Basic Science Research Program through the National Research 
Foundation of Korea (NRF) funded by the Ministry of Science and ICT (NRF-2017R1D1A1B03033758 to YS Lee and NRF-2020R1A2B5B01001936 to SW Chung).

\section{Footnote}

Conflicts of Interest: All authors have completed the ICMJE uniform disclosure form (available at http://dx.doi. org/10.21037/atm.2020.02.32). The authors have no conflicts of interest to declare.

Ethical Statement: The authors are accountable for all aspects of the work in ensuring that questions related to the accuracy or integrity of any part of the work are appropriately investigated and resolved.

Open Access Statement: This is an Open Access article distributed in accordance with the Creative Commons Attribution-NonCommercial-NoDerivs 4.0 International License (CC BY-NC-ND 4.0), which permits the noncommercial replication and distribution of the article with the strict proviso that no changes or edits are made and the original work is properly cited (including links to both the formal publication through the relevant DOI and the license). See: https://creativecommons.org/licenses/by-nc-nd/4.0/.

\section{References}

1. Codding JL, Keener JD. Natural History of Degenerative Rotator Cuff Tears. Curr Rev Musculoskelet Med 2018;11:77-85.

2. Oh JH, Park MS, Rhee SM. Treatment Strategy for Irreparable Rotator Cuff Tears. Clin Orthop Surg 2018;10:119-34.

3. Tonotsuka H, Sugaya H, Takahashi N, et al. Preoperative Pain Control in Arthroscopic Rotator Cuff Repair: Does It Matter? Clin Orthop Surg 2019;11:192-9.

4. Lädermann A, Denard PJ, Burkhart SS. Management of failed rotator cuff repair: a systematic review. J ISAKOS 2016;1:32-7.

5. Choi S, Yang H, Kang H, et al. Treatment of Large and Massive Rotator Cuff Tears: Does Infraspinatus Muscle Tear Affect Repair Integrity? Clin Shoulder Elbow 2019;22:203-9.

6. Kim HB, Jae CY, Jeung YJ. Evaluation of Muscular Atrophy and Fatty Infiltration Using Time-zero Magnetic Resonance Imaging as Baseline Data, After Rotator Cuff Repair. Clin Shoulder Elbow 2019;22:70-8.
7. Gladstone JN, Bishop JY, Lo IK, et al. Fatty infiltration and atrophy of the rotator cuff do not improve after rotator cuff repair and correlate with poor functional outcome. Am J Sports Med 2007;35:719-28.

8. Uezumi A, Fukada S, Yamamoto N, et al. Mesenchymal progenitors distinct from satellite cells contribute to ectopic fat cell formation in skeletal muscle. Nat Cell Biol 2010;12:143-52.

9. Joshi SK, Liu X, Samagh SP, et al. mTOR regulates fatty infiltration through SREBP-1 and PPAR $\gamma$ after a combined massive rotator cuff tear and suprascapular nerve injury in rats. J Orthop Res 2013;31:724-30.

10. Hamrick MW, McGee-Lawrence ME, Frechette DM. Fatty Infiltration of Skeletal Muscle: Mechanisms and Comparisons with Bone Marrow Adiposity. Front Endocrinol (Lausanne) 2016;7:69.

11. Pittenger MF, Mackay AM, Beck SC, et al. Multilineage potential of adult human mesenchymal stem cells. Science 1999;284:143-7.

12. Bianco ST, Moser HL, Galatz LM, Huang AH. Biologics and stem cell-based therapies for rotator cuff repair. Ann N Y Acad Sci 2019;1442:35-47.

13. Gumucio JP, Korn MA, Saripalli AL, et al. Agingassociated exacerbation in fatty degeneration and infiltration after rotator cuff tear. J Shoulder Elbow Surg 2014;23:99-108.

14. Nakagaki K, Ozaki J, Tomita Y, et al. Fatty degeneration in the supraspinatus muscle after rotator cuff tear. J Shoulder Elbow Surg 1996;5:194-200.

15. Pagano AF, Brioche T, Arc-Chagnaud C, et al. Short-term disuse promotes fatty acid infiltration into skeletal muscle. J Cachexia Sarcopenia Muscle 2018;9:335-47.

16. Leite RD, Prestes J, Bernardes CF, et al. Effects of ovariectomy and resistance training on lipid content in skeletal muscle, liver, and heart; fat depots; and lipid profile. Appl Physiol Nutr Metab 2009;34:1079-86.

17. Schubert MF, Noah AC, Bedi A, et al. Reduced Myogenic and Increased Adipogenic Differentiation Capacity of Rotator Cuff Muscle Stem Cells. J Bone Joint Surg Am 2019;101:228-38.

18. Yin H, Price F, Rudnicki MA. Satellite cells and the muscle stem cell niche. Physiol Rev 2013;93:23-67.

19. Perry RL, Rudnick MA. Molecular mechanisms regulating myogenic determination and differentiation. Front Biosci 2000;5:D750-67.

20. Rudnicki MA, Schnegelsberg PN, Stead RH, et al. MyoD or Myf-5 is required for the formation of skeletal muscle. Cell 1993;75:1351-9. 
21. Megeney LA, Kablar B, Garrett K, et al. MyoD is required for myogenic stem cell function in adult skeletal muscle. Genes Dev 1996;10:1173-83.

22. Asfour HA, Allouh MZ, Said RS. Myogenic regulatory factors: The orchestrators of myogenesis after 30 years of discovery. Exp Biol Med (Maywood) 2018;243:118-28.

23. Sciorati C, Clementi E, Manfredi AA, et al. Fat deposition and accumulation in the damaged and inflamed skeletal muscle: cellular and molecular players. Cell Mol Life Sci

Cite this article as: Lee YS, Kim JY, Chung SW. Rotator cuff muscle stem cells: the double-edged sword in the skeletal muscle. Ann Transl Med 2020;8(11):717. doi: 10.21037/ atm.2020.02.32
2015;72:2135-56.

24. Lee YS, Kim JY, Oh KS, et al. Fatty acid-binding protein 4 regulates fatty infiltration after rotator cuff tear by hypoxia-inducible factor 1 in mice. J Cachexia Sarcopenia Muscle 2017;8:839-50.

25. Lee YS, Kim JY, Kim KI, et al. Effect of Fatty AcidBinding Protein 4 Inhibition on Rotator Cuff Muscle Quality: Histological, Biomechanical, and Biomolecular Analysis. Am J Sports Med 2019;47:3089-99. 